\title{
Moisture Diffusion in Alumina Green Compact Containing Polyvinyl Alcohol Binder
}

\author{
Yutaka SAITO, Junichi NYUMURA, Kiyoteru FUKAI, Yao ZHANG, \\ Nozomu UCHIDA and Keizo UEMATSU \\ Department of Chemistry, Nagaoka University of Technology, 1603-1, Kamitomioka, Nagaoka-shi 940-2188
}

\author{
PVA バインダーを含むアルミナ成形体中の水分拡散 \\ 斉藤 豊 $\cdot$ 入村純一·深井清輝·張 躍 $\cdot$ 内田 希·植松敬三 \\ 長岡技術科学大学化学系, 940-2188 長岡市上富岡町 1603-1
}

\begin{abstract}
Moisture content is one of the most important factors governing both structure and properties of green powder compacts of ceramics made through a compaction process. To control the moisture content in powder granules, it is necessary to understand kinetic changes of moisture content in granules, and pressed compacts. The apparent diffusion coefficient of moisture was directly measured for powder compacts containing polyvinyl alcohol (PVA) by following the weight change of the specimen. The parameters examined in this paper were size of specimen, forming pressure, average relative humidity and binder content. The observed rate of change was clearly affected by the PVA content in the compact. Examination of the distribution of PVA in the granules and compacts using optical microscopy (using immersion liquid method) was found to be nonuniform. The diffusion path consisted of an alternate sequence of thin layers of PVA-rich regions and thick layers of PVA-poor regions. The PVA-rich layers had a non-homogeneous structure which contained open pores.

[Received October 1, 2001; Accepted February 15, 2001]
\end{abstract}

Key-words : Alumina, Moisture, Diffusion coefficient, Green compact, Poly (vinyl alcohol)

\section{Introduction}

Moisture plays an important role in compaction forming, which is used frequently in the commercial production of ceramics. It affects the glass transition temperature of binder and thus the deformation behavior of powder granules under an applied stress. Past studies ${ }^{1-7)}$ have clarified the effect of moisture content on the compaction behavior of granules and the structure of resultant compacts for both die pressing and cold isostatic pressing (CIP) of preformed compacts. In these studies, the moisture contents in the system were equilibrated with the humidity in the atmosphere before compaction. In practice, however, the moisture content in the system may vary with time if the relative humidity of surrounding atmosphere is different from what the granules were equilibrated previously. This is very likely in the case of real production processes. However, the kinetics of moisture change in the granules as well as in the preformed powder compacts have not been well studied.

This paper reports the kinetics for the change of moisture content in alumina powder compact which contains PVA as a binder and discusses the relationship between the diffusion coefficient and the internal structure of powder compact. This is an important system, which is widely applied in the commercial production of ceramics and the results are likely applicable to other systems. Phenomenological diffusion controlled kinetics is assumed in the analysis to obtain diffusion coefficients as a representative kinetic constant. Although the value obtained is only apparent, it will be conveniently used for estimating the equilibration time for various general cases, i.e., for specimens of different size and geometry.

The experiment of this study applies a dynamic diffusion controlled process, in which moisture is diffused from the surface of a spherical green compact. The similar situation often happens in a place of commercial production of ceramics. The weight change of the compact is followed after a step change of humidity in the surrounding atmosphere to determine the change of total moisture content with time. Assumptions in the analysis are as follows; (1) the moisture content at the surface reaches the final equilibrium value instantly after the step change and (2) the diffusion coefficient is constant for all moisture content. The parameters examined are size of specimen, forming pressure, average relative humidity and binder content. The diffusion coefficients obtained are conveniently applied to estimate the kinetics for the change of moisture content in the granules.

\section{Experimental}

Commercial alumina (160SG-1; Showadenko Ltd.) and PVA (PVA205; Kuraray, average degree of polymerization 500 , saponification degree $88.0 \%$ ) were used as starting materials. They were mixed with distilled water in an attrition mill for $24 \mathrm{~h}$ to make slurries of various compositions (by weight, the formulations were alumina: 100, PVA: 1-3, distilled water: 100). The slurry was spray dried to make the granules, which were then isostatically pressed at 20-200 MPa in a thin rubber bag to make green compacts of approximately a spherical shape. The compacts were reshaped into sphere of various sizes (diameter: $1-2 \mathrm{~cm}$ ) with a knife and sandpaper. Some of the compacts were heated to $1000^{\circ} \mathrm{C}$ for $1 \mathrm{~h}$ in air to remove binder to make the specimen of 0 mass $\%$ PVA content and to observe the internal structure. A part of granules were also heated to use observation of internal structure. Specimens were dried at $110^{\circ} \mathrm{C}$ for over $24 \mathrm{~h}$ and cooled in a desiccator before diffusion experiment. The pore size distribution of specimen was determined by mercury porosimetry (Micromeritics Poresizer 9320, Shimadzu). Internal structures of granules and compacts were examined with the liquid immersion technique. ${ }^{8)}$ That is, the granules before and after binder removal were immersed in methylene iodide $(n=1.74)$. The compacts with and without binder removal were thinned to about 0.2 $\mathrm{mm}$ with grinding paper, and were immersed in methylene 


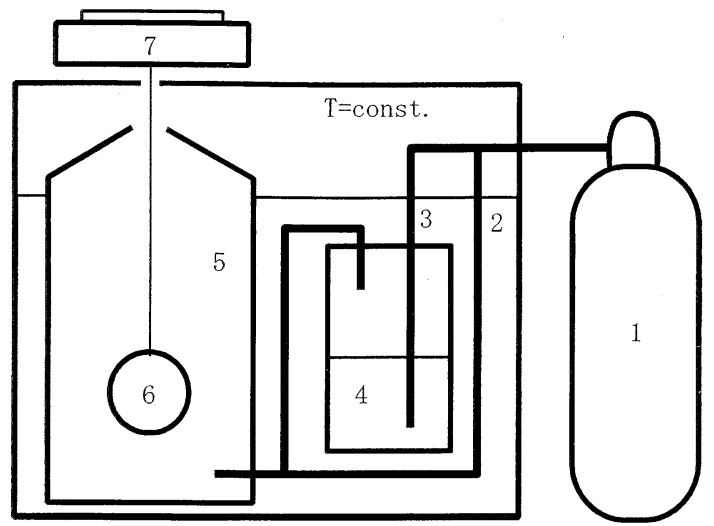

Fig. 1. Experimental set-up: 1 air cylinder, 2 dry line, 3 wet line, 4 bubbling tank, 5 chamer, 6 specimen, 7 electric balance.

iodide and 1-bromonaphthalene $(n=1.69)$, respectively. Micrographs were taken with an optical microscope in the transmission mode. Micrograph of the granules was also taken by a scanning electron microscope (SEM; JSM5310LV, JEOL).

Figure 1 shows the experimental set-up, schematically. Custom-made equipment was used to measure the weight change with humidity in the atmosphere. A dry air from an air cylinder is divided into "dry" and "wet" lines. The air in the "wet" line is passed through a bubbling tank half filled with water. The humidity in the specimen chamber was adjusted by mixing the dry air and the wet air. The temperature in the specimen chamber was controlled by placing it in a constant temperature bath. Four specimens were placed in a specimen chamber, and their weights were measured by hanging them under an electric balance at specific times. The weight change of the specimen was followed after the humidity in the chamber was changed step-wise by changing the flow rate ratio of dry-air to wet-air. Weight change was followed until no further weight change was observed.

In the experiment, initial moisture distribution in alumina compacts was uniform, and the surface of compacts was exposed to fresh air in the sufficient airflow. The present case corresponds to the "non-steady state diffusion in a sphere of surface concentration constant," the mathematical treatment of which has been given in standard textbook. $\left.{ }^{9}\right)$ In this condition, the total amount of moisture entering the compact sphere is expressed as,

$$
\frac{M_{\mathrm{t}}}{M_{\infty}}=1-\frac{6}{\pi^{2}} \sum_{n=1}^{\infty} \frac{1}{n^{2}} \exp \left(-\frac{D n^{2} \pi^{2} t}{a^{2}}\right)
$$

where $M_{\mathrm{t}}$ is the weight change from the moment of humidity changed $(t=0)$ to time $t=t$ (moisture uptake) and $M_{\infty}$ the corresponding to the moisture uptake at infinite time. The ratio of $M_{\mathrm{t}} / M_{\infty}$ corresponds to the normalized moisture uptake.

\section{Results}

Figure 2 shows the normalized weight changes with time for compact spheres of two sizes at $30^{\circ} \mathrm{C}$ in $70 \%$ R.H. (initial $60 \%$ R.H.). Starting moisture content is 0.27 mass $\%$. The moisture contents in the alumina compacts increased rapidly with time immediately after the step change of humidity. The rate of change decreased gradually with time and became zero after a long period of time. The rate is clearly higher in the small specimen than the large one. The moisture contents reached constant values in about 200 and 800 minutes for small and large specimens, respectively.

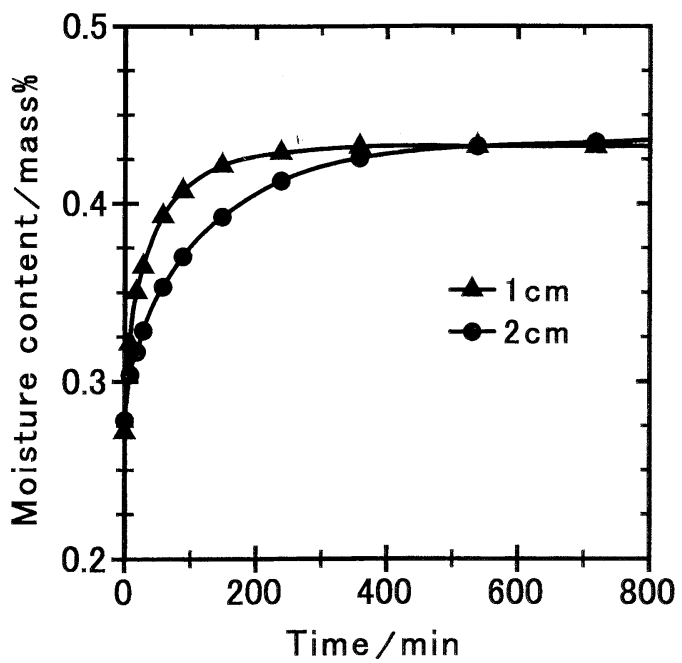

Fig. 2. Weight change for alumina compact sphere of various sizes: PVA content 2 mass $\%$, pressed at $100 \mathrm{MPa}$.

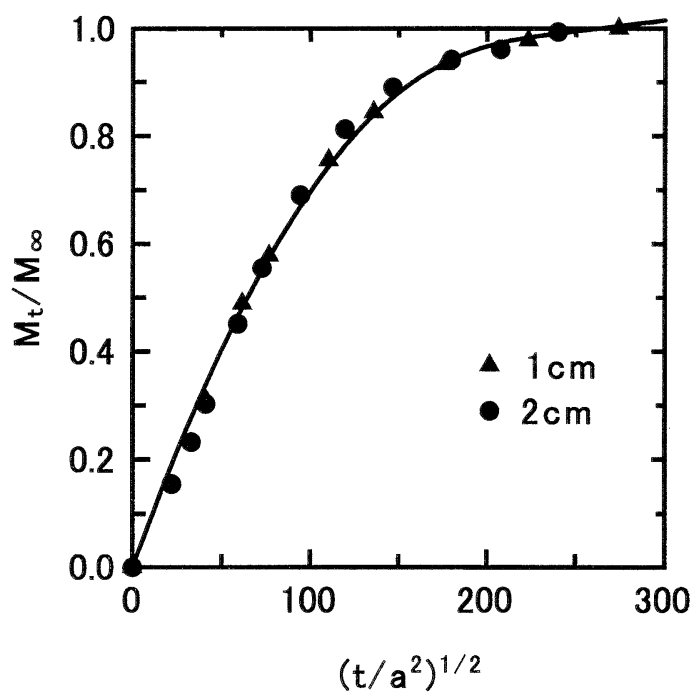

Fig. 3. Uptake curve for alumina compact sphere of various sizes: PVA content 2 mass $\%$, pressed at $100 \mathrm{MPa}$.

The final moisture content is 0.43 mass $\%$ for both specimens.

Figure 3 shows the normalized uptake curves for alumina compacts of two sizes as a function of time at $30^{\circ} \mathrm{C}$ in $70 \%$ R.H. (initial $60 \%$ R.H.). The solid line represents the calculated uptake with an assumed diffusion coefficient $(1.0 \times$ $\left.10^{-5} \mathrm{~cm}^{2} / \mathrm{s}\right)$. All experimental results agreed with the calculated curve very well. A single diffusion coefficient was deduced from specimens of different sizes. Results on other conditions were also represented with Eq. 1 very well, provided the changes in the humidity were small (below $20 \%$ ).

Figure 4 shows the effect of forming pressure on the diffusion coefficient determined from the sorption and desorption experiments. In the sorption experiment, specimens were placed in $70 \%$ R.H. (initially $60 \%$ R.H.) and the moisture contents in the specimens increased with time. In the desorption experiment, specimens were placed in $60 \%$ R.H. (initially $70 \%$ R.H.), and the moisture content decreased 


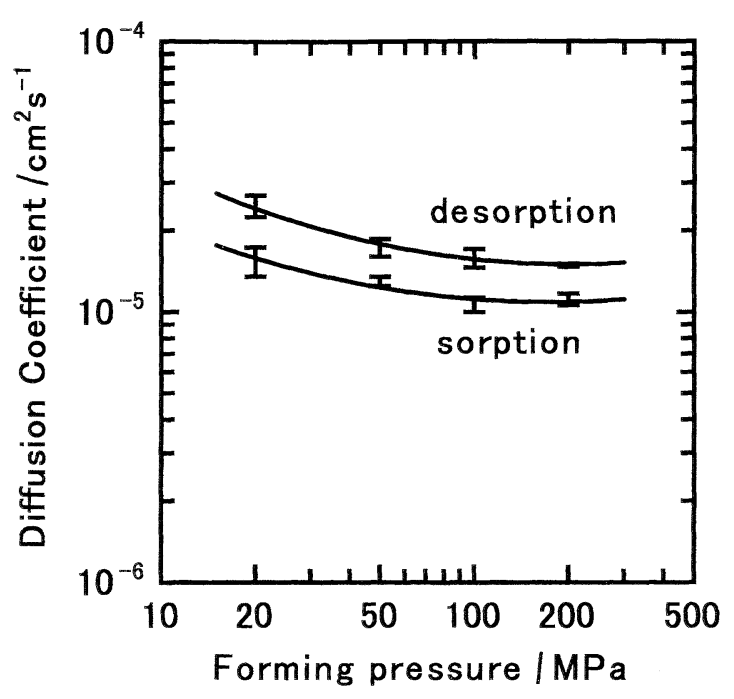

Fig. 4. Relation ship between diffusion coefficient and forming pressure: PVA content 2 mass $\%$, specimens diameter $1.5 \mathrm{~cm}$.

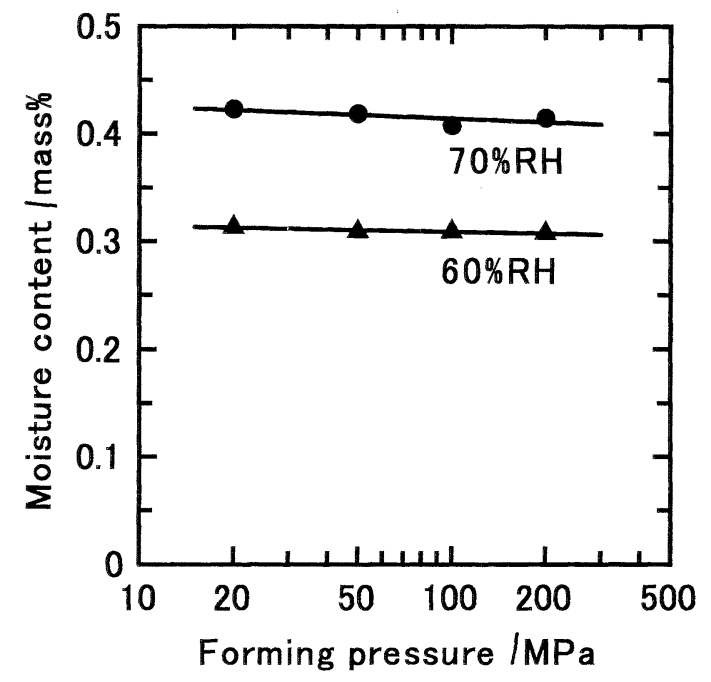

Fig. 5. Relation ship between saturated moisture content and forming pressure: PVA content 2 mass $\%$, specimens diameter 1.5 $\mathrm{cm}$.

with time. The diffusion coefficient decreased slightly with increasing forming pressure. The diffusion coefficient also varied with the direction of weight change; the sorption process is slightly slower than the desorption process.

Figure 5 shows the effect of forming pressure on saturated moisture content at $30^{\circ} \mathrm{C}$ in $60 \%$ R.H. and $70 \%$ R.H. The moisture content only slightly decreased with increasing forming pressure, and almost the same moisture contents were obtained at these relative humidity.

Figure 6 shows the cumulative pore size distribution for powder compacts prepared at various pressures. The majority of pores have a size below $0.2 \mu \mathrm{m}$. This is understandable, since these pores correspond to the space between primary alumina particles of average size $0.5 \mu \mathrm{m}$. With increasing forming pressure, the total volume of pores decreases, and the most frequent pore size, corresponding to the sharp rise of cumulative pore volume, also decreases.

Figure 7 shows the change of diffusion coefficient with PVA content at $30^{\circ} \mathrm{C}$ in $70 \%$ R.H. (initial $60 \%$ R.H.), and

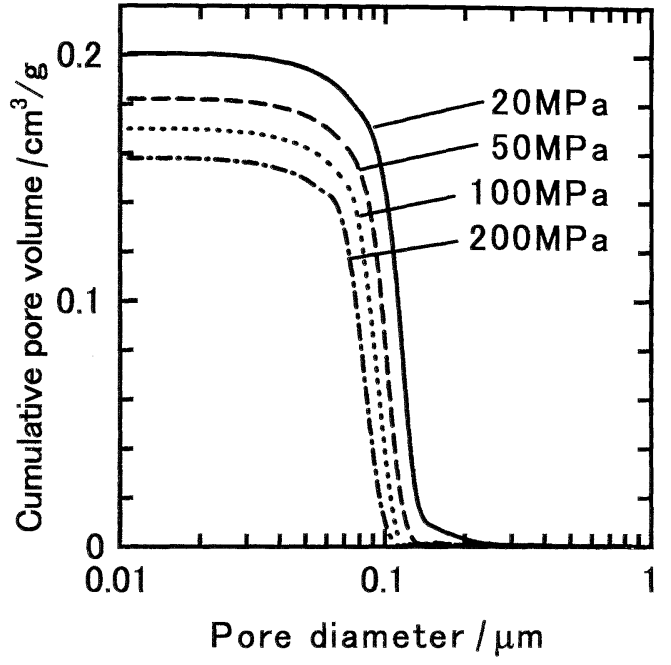

Fig. 6. Cumulative pore size distribution of powder compacts prepared at various forming pressure: PVA content 2 mass $\%$, specimens diameter $1.5 \mathrm{~cm}$.

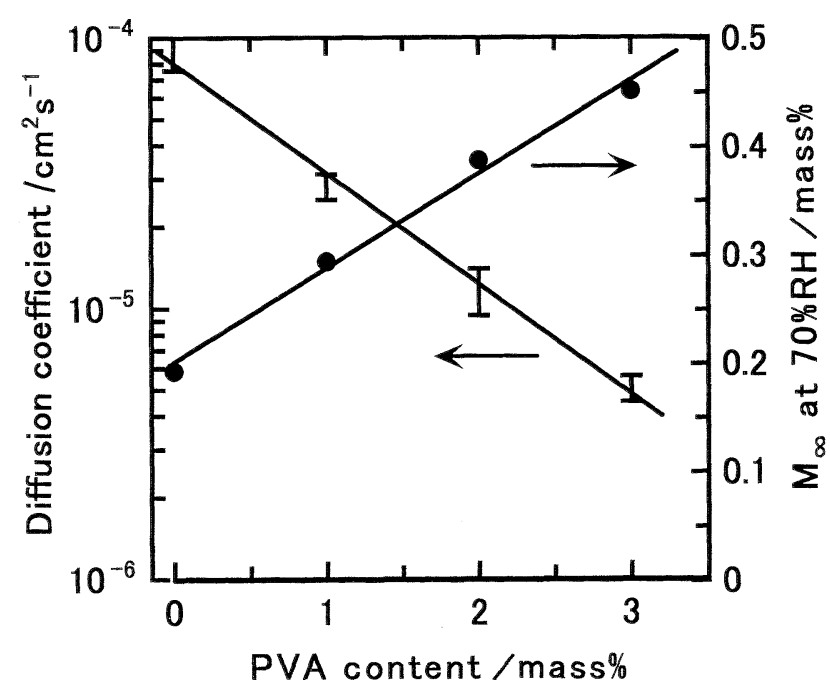

Fig. 7. Relation ship between diffusion coefficient, saturated moisture content and PVA content: specimen diameter $1.5 \mathrm{~cm}$, pressed at $100 \mathrm{MPa}$.

the change of saturated moisture content at $30^{\circ} \mathrm{C}$ in $70 \%$ R.H. The diffusion coefficient decreased markedly with increasing PVA content. The diffusion coefficient of the compact, which contains PVA, is much smaller than that containing no PVA. The binder clearly reduced the diffusion coefficient drastically. The saturated moisture content increased with increasing PVA content.

Figure 8 shows the cumulative pore size distribution for powder compacts prepared at various PVA contents. The majority of pores have a size below $0.2 \mu \mathrm{m}$. With increasing PVA content, the total volume of pores decreases, and the pore size corresponding to a sharp rise of cumulative pore size also decreases.

Figure 9 shows the change of diffusion coefficient with relative humidity at $30^{\circ} \mathrm{C}$. The diffusion coefficient is much higher for all humidity range examined in specimens without binder. The diffusion coefficient tends to decrease with increasing relative humidity. In specimen of PVA 2 


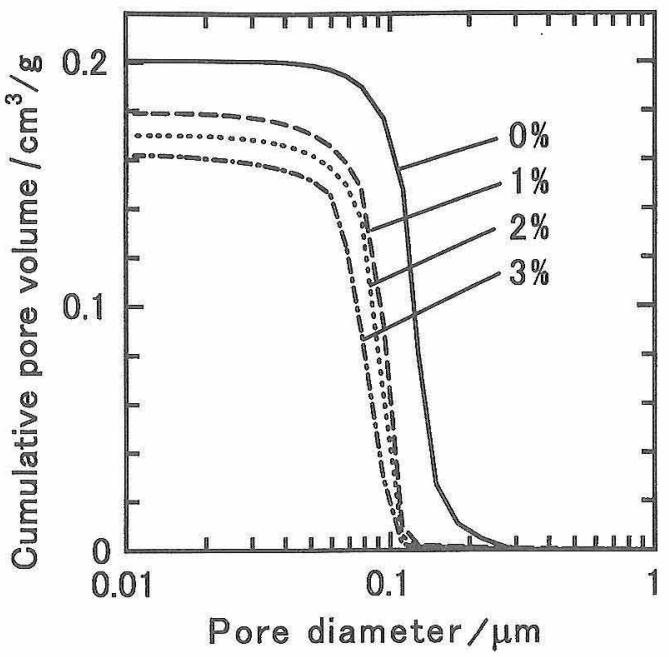

Fig. 8. Cumulative pore size distribution of powder compacts prepared at various PVA content: specimen diameter $1.5 \mathrm{~cm}$, pressed at $100 \mathrm{MPa}$.

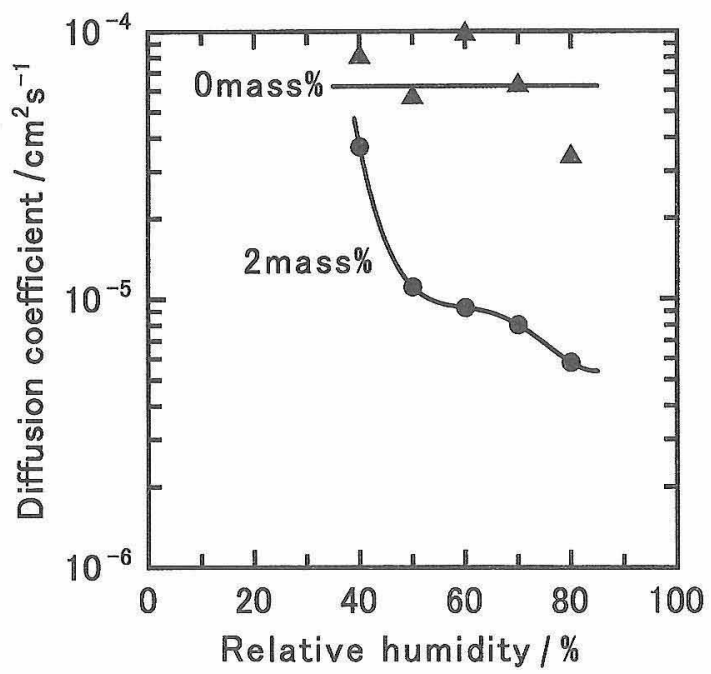

Fig. 9. Relationship between diffusion coefficient and relative humidity: specimen diameter $1.5 \mathrm{~cm}$, pressed at $100 \mathrm{MPa}$.

mass $\%$, the diffusion coefficient increased markedly at $40 \%$ R.H., and reached almost the same value as PVA-free specimen. In PVA-free specimen, the diffusion coefficient shows large scatter, since a little and a rapid weight change made the measurement very difficult.

Figure 10 shows the effect of relative humidity on saturated moisture content at $30^{\circ} \mathrm{C}$. Moisture contents increased with increasing humidity. They were almost the same up to $40 \%$ R.H. A significant difference was noted among them at high relative humidity.

Figures 11 and Fig. 12 show the internal structures of grantles containing 2 mass\% of PVA and their compact formed at $100 \mathrm{MPa}$, respectively. Granules have nearly spherical shape and various sizes. Dark shell is noted around all granules (Fig. 11(a)), and they disappeared after the binder was removed by heating (Fig. 11(b)). The dark shell corresponds to segregated PVA, which reduces the transmission of light due to its mismatching of refractive index with the immersion liquid. The distribution of PVA is

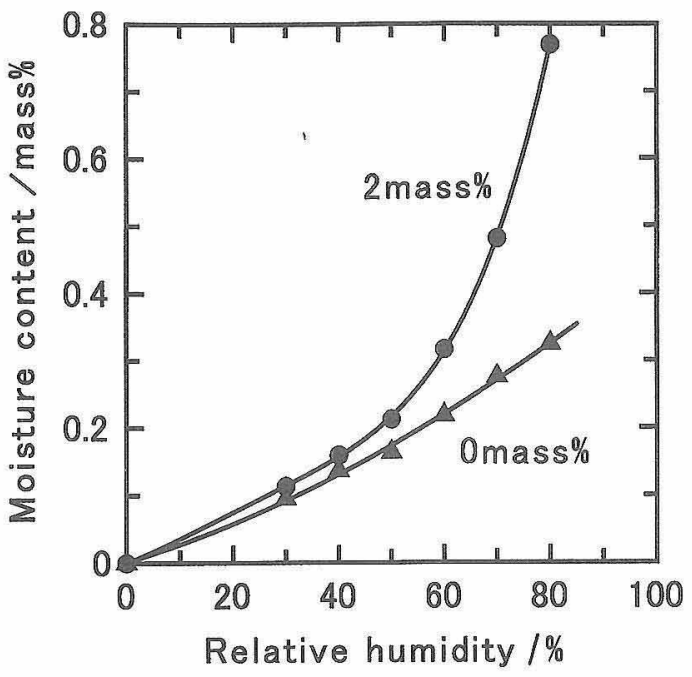

Fig. 10. Relationship between saturated moisture content and relative humidity: specimen diameter $1.5 \mathrm{~cm}$, pressed at $100 \mathrm{MPa}$.
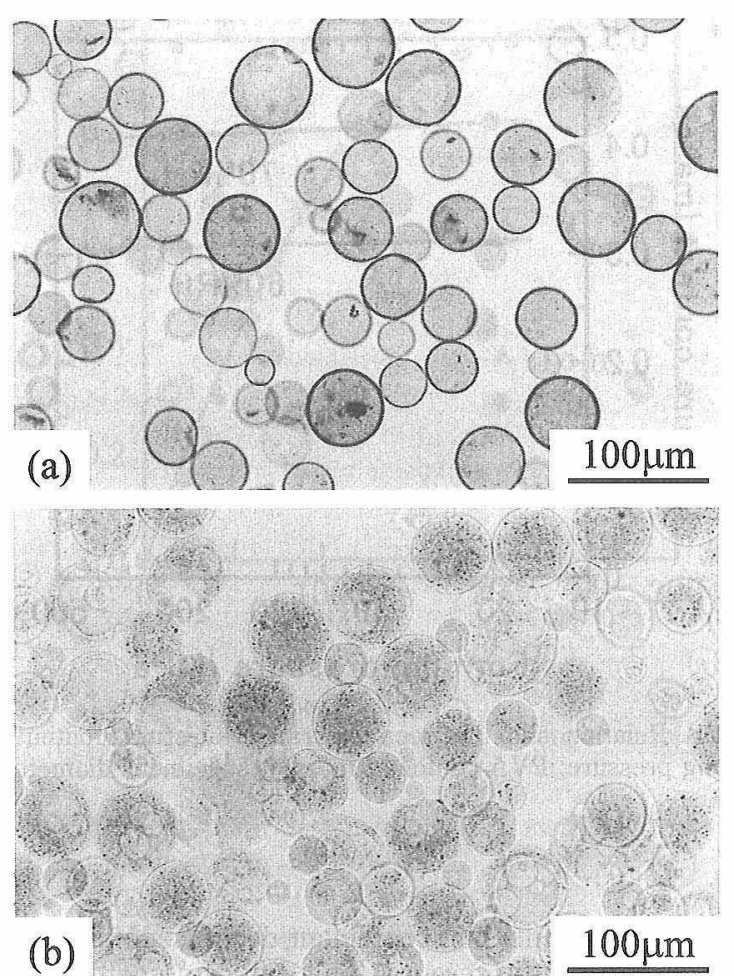

Fig. 11. Liquid immersion optical micrograph of transmission mode for alumina granules: (a) as spray-dried, (b) after binder removal.

clearly non-uniform in the compact. In the powder compact, the PVA-rich regions on the surface of granules are transformed to a continuous three-dimensional network structure (Fig. 12(a)). When the location of focus was varied, the similar structure appears at any location. The structure also disappeared after the binder removal (Fig. 12(b)). A part of PVA must be present inside the granules, although this is difficult to show directly through the observation. It should be added at this point that the immersion liquid penetrated into the compact readily. The PVA-rich layer at the gran- 

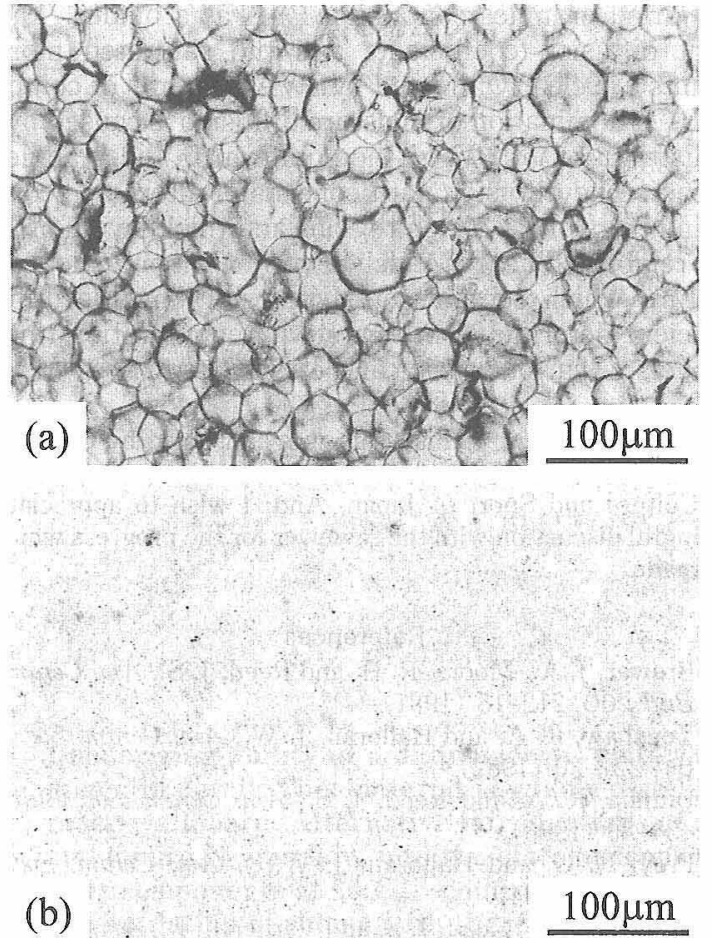

Fig. 12. Internal structure of green compacts observed with the liquid immersion optical microscope transmission mode: (a) as pressed (b) after binder removal.

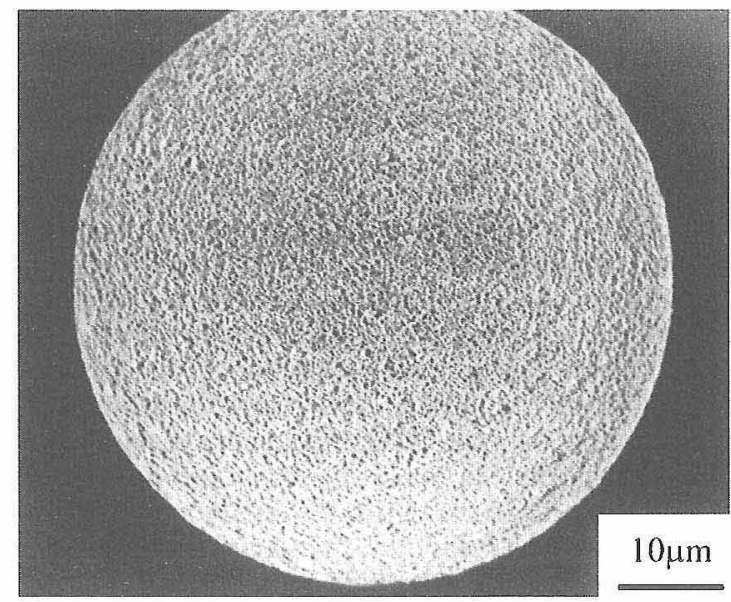

Fig. 13. SEM micrograph of granule.

ules boundaries clearly has open pores.

Figure 13 shows the scanning electron micrograph of the granule containing 2 mass $\%$ of PVA. Alumina particles are clearly visible. The surface is only partially covered with PVA. Fine pores are present among the alumina particles at the surface of the granule. The capillaries between particles are only partially filled with PVA.

\section{Discussion}

The kinetic for the change of moisture content is explained in terms of the diffusion process in the compact. The rate of moisture absorption into sample surface appears to be much faster than that of the diffusion process, because the apparent diffusion coefficient was not affected by the specimen diameter in this work. It justifies the assumptions made in the application of diffusion equation used in this study. The equation can be applied accurately for the determination of apparent diffusion coefficient in green compacts. A slight difference in the diffusion coefficient for sorption and desorption process (Fig. 4) may reflect a small influence of surface process. This effect is neglected in the subsequent discussion.

The structure of compact should be recalled to discuss the marked decrease of apparent diffusion coefficient with increasing PVA content. The structure in Fig. 12 shows that along the diffusion path, the structure consists of alternate sequence of thin layers of PVA-rich regions and thick layers of PVA-poor regions. The similar structure has been also reported in other study. ${ }^{8)}$ In the moisture diffusion through these alternate layers, the kinetic is governed by the slower diffusion through these layers.

It is interesting to make a rough estimate for the apparent diffusion coefficient for the PVA-rich layer. The apparent diffusion coefficient, $D$, of the compact is given by,

$$
\frac{l_{\text {rich }}+l_{\text {poor }}}{D}=\frac{l_{\text {rich }}}{D_{\text {rich }}}+\frac{l_{\text {poor }}}{D_{\text {poor }}}
$$

where, $l_{\text {rich }}$ and $l_{\text {poor }}$ are the ratio of the thickness of PVArich layer and PVA-poor region, respectively, and $D_{\text {rich }}$ and $D_{\text {poor }}$ are the diffusion coefficients in each phase. ${ }^{10)}$ The ratio of thickness is estimated to be 1:100 from the optical micrograph in Fig. 12 for the compact with 2 mass\% PVA. The diffusion coefficient for the PVA-poor region is estimated to be about $10^{-4} \mathrm{~cm}^{2} / \mathrm{s}$ in Fig. 4.

These values give the apparent diffusion coefficient, $D_{\text {rich }}, 1 \times 10^{-9} \mathrm{~cm}^{2} / \mathrm{s}$. This value is much larger than the diffusion coefficient in bulk PVA phase, $D_{\text {rich }}$, about $10^{-11}$ $\mathrm{cm}^{2} / \mathrm{s} .{ }^{11)}$ Considering that approximately $60 \%$ of the diffusion path is blocked by the alumina particles in the present system, above apparent diffusion coefficient for the PVArich layer is more than 100 times larger than that in the bulk PVA.

The PVA-rich layer must have non-homogeneous structure. It may contain open pores. If it does not contain open pores forming a continuous film, its thickness must be very thin at least certain places. This structure is consistent to the SEM micrograph shown in Fig. 13. It suggests the presence of open pores on the surface of the granules. These open pores must have survived the compaction process and at least some of them remain in the compact. The easy penetration of immersion liquid is also consistent to the presence of open pores in the PVA-rich layer. This liquid is a poor solvent to PVA and should not penetrate readily into the compact if a continuous film of PVA is present.

The value of diffusion coefficient in porous materials can be related to pore structure parameters by defining

$$
D=D_{\mathrm{K}} \phi / \beta
$$

where $D_{\mathrm{K}}$ is the Knudsen diffusion coefficient in single cylindrical capillary. The parameter $\phi$ is the porosity. The factor $\beta$ is tortuosity of the pore network. ${ }^{12)}$ Knudsen diffusion coefficient is

$$
D_{\mathrm{K}}=\frac{2}{3} r\left(\frac{8 R T}{\pi M}\right)^{1 / 2}
$$

where $r$ is capillary radius, $R$ is gas constant, $T$ is temperature, and $M$ is molecular weight. ${ }^{13}$ For present experimental condition $\left(r=0.5 \times 10^{-5} \mathrm{~cm}, T=303 \mathrm{~K}, M=18\right), D_{\mathrm{K}}$ is calculated as $6.3 \times 10^{-4} \mathrm{~cm}^{2} / \mathrm{s}$. The value of $\beta$ is estimated as 2.5 , since $D=1 \times 10^{-4} \mathrm{~cm}^{2} / \mathrm{s}$, and $\phi=0.4$ for compact without binder. The pore geometry of the compact must be very complicated. If all pores were straight, the factor $\beta$ should be one. With increasing $\beta$, the pore geometry 
becomes complex. The value 2.5 for $\beta$ appears resonable.

Moisture adsorption of the compact is dominated by two factors. One is absorption into PVA phase and the other is reversible moisture adsorption into capillaries at contact region between primary particles in green compact. The linear increase of the moisture adsorption with PVA content (Fig. 7) can be explained by the combination of these two factors. Assuming that the moisture content in the capillary region is 0.20 mass\% (estimation from the moisture content of the compact without PVA) for all PVA content, the moisture content in the PVA is derived by subtracting 0.20 from total amount of moisture for each. Therefore, moisture contents in PVA to mass of compacts are estimated to 0.10 0.19 and 0.25 mass $\%$ for PVA content 1,2 and 3 mass $\%$, respectively. And moisture content in PVA phase is estimated to $10.0,9.5$, and 8.3 mass $\%$ for each. Decrease of estimated moisture content with increasing PVA content suggests that PVA fills the interstices between primary particles, or the amount of capillary moisture adsorption was decreased. Absorption behavior of moisture in a lump of PVA must not change with PVA content of compacts. The result of mercury penetration supports this point since it showed the decrease of porosity and pore size with increasing PVA content.

The diffusion coefficients determined in this study can be applied to estimate the equilibration time for compacts of various sizes. The estimation shows surprising results in some cases, since the time required for a diffusion process is proportional to the square of representative size of the material. For instance, if a large compact is considered, e.g., a sphere of $20 \mathrm{~cm}$ in diameter, the equilibration time is $8 \times$ $10^{4} \mathrm{~min}$, or over $50 \mathrm{~d}$. The time for equilibration is $0.02 \mathrm{~min}$ or approximately $1 \mathrm{~s}$ for a granule of the size $0.2 \mathrm{~mm}$, if the same mechanism and diffusion coefficient applies for a granule. These extremely long and short equilibration times may account for variation of product property, when the significance of diffusion is neglected.

\section{Conclusion}

To provide guidelines for moisture control in granules during pressing, the apparent moisture diffusion coefficients are determined in a powder compact which is made from spray-dried granules containing PVA as a binder. The apparent diffusion coefficients and the saturated moisture amounts are clearly affected by PVA contents of compacts. The PVA domination of moisture diffusion is caused by that the distribution of PVA is non-uniform in the granule and compact. The diffusion path consists of alternate sequence of thin layers of PVA-rich regions and thick layers of PVApoor regions. The PVA-rich layer has non-homogeneous structure which contains open pores. Using the diffusion coefficient determined in this study, equilibration time for compacts of various sizes can be estimated.

Acknowledgement This study was supported by Grant-in-Aid for Scientific Research (No. 11305045) by the Ministry of Education, Culture and Sport of Japan. And, I wish to appreciate the meaningful discussion with the reviewer for the progress which has been made.

References

1) Brewer, J. A., Moore, R. H. and Reed, J. S., Am. Ceram. Soc. Bull., 60, 212-15 (1981).

2) Youshaw, R. A. and Halloran, J. W., Am. Ceram. Soc. Bull., 61, 227-30 (1982).

3) Dimilia, R. A. and Reed, J. S., Am. Ceram. Soc. Bull., 62, 484-88 (1983).

4) Frey, R. G. and Halloran, J. W., J. Am. Ceram. Soc., 67, 199-203 (1984).

5) Mosser, B. D., Reed, J. S. and Varner, J. R., Am. Ceram. Soc. Bull., 71, 105-09 (1981).

6) Liu, D.-M. and Fu, C.-T., Ceram. Int., 22, 67-72 (1996),

7) Tanaka, H., Fukai, S., Uchida, N. and Uematsu, K., J. Am. Ceram. Soc., 77, 3077-80 (1994).

8) Zhang, Y., Uchida, N. and Uematsu, K., J. Mater. Sci., 30, 1357-60 (1995).

9) Crank, J., "The Mathematics of Diffusion," 2nd ed., Oxford University Press (1975) pp. 89-103.

10) Crank, J., "The Mathematics of Diffusion," 2nd ed., Oxford University Press (1975) pp. 266-85.

11) Yamasaki, A. and Mizoguchi, K., J. Appl. Polym. Sci., 53, 1669-74 (1994).

12) Garboczi, E. J., Cem. Concr. Res., 20, 591-601 (1990).

13) Youngquist, G. R., "Diffusion and Flow of Gases in Porous Solids," Flow Through Porous Media, Am. Chem. Soc. (1970) pp. 57-69. 